\title{
Chapter 9 \\ Essentials Over Peripherals: The CVIF Dynamic Learning Program
}

\author{
Christopher C. Bernido and Maria Victoria Bernido
}

\section{Introduction}

Sustainable cost-effective optimized education for the majority, if not for all, can be achieved if an academic program can meld (i) a rapidly changing technology-driven educational landscape, (ii) results of neuroscientific research enhanced by advanced medical technologies, and (iii) the evident natural curiosity and biological habitforming capacity of humans. A conspicuous trademark of the evolving educational environment is the rapidly expanding knowledge bank and online libraries linked by Google and YouTube that can be easily and individually accessed by learners, thus bypassing the traditional role of teachers and classroom textbooks. Positron emission tomography scans of the brain are now routine, shedding light on brain activity during sleep and awake periods. Then there is the commonly observable high degree of engagement, both positive and negative, with information and communications gadgets displayed by very young people, even those in preschool. More developments in online resources, medical technologies, and response of the populace, yet unimagined, are on the horizon, even as common talk mentions the Fourth Industrial Revolution brought about by advanced automation and digitization, robotics, and artificial intelligence, and the internet. Because of these, there is an urgent need for the twenty-first century workforce to be educated and trained so as to be equipped with collaborative and communication skills, critical thinking, creativity, and the abilities to learn new skills and solve highly complex problems. "A nation's precious human capital is nurtured through education and promoted through the labor market. This is the national resource that more than any other will determine success in terms

C. C. Bernido $(\bowtie) \cdot M$. V. Bernido

Central Visayan Institute Foundation, Jagna, Bohol, Philippines

e-mail: cbernido.cvif@gmail.com 
of GDP, investment environment and so on as nations compete in the global market economy."

The complexity and breadth of issues posed to educators by twenty-first century technological developments make it tempting for governments and educators to adopt (i) huge budget curricular reforms; and (ii) a tech-for-tech approach-a swarm of costly high technology gadgets and robotics kits introduced in schools and colleges. However, challenges remain formidable in the delivery of quality education for the general population, in the humanities and social sciences, and in particular, in science, technology, engineering, and mathematics (STEM), which is a cause for concern, since economic and political power has been linked to the strength of human resources in STEM disciplines. ${ }^{2}$ Advanced and developing countries duly appropriate large portions of their national budget to education. However, huge budgets do not necessarily create huge impact in educational outcomes. ${ }^{3}$ As noted in Singapore, "Recent OECD findings show that higher expenditure does not guarantee better student performance."4 The Royal Society of the United Kingdom, in comprehensive state-of-thenation reports on school science and mathematics leading up to higher STEM education, states, "It is clear from the evidence presented in this report that, as a whole, our education systems are failing to maximize the numbers of students who could go on to become STEM undergraduates". 5

\section{A Package of Solutions: The CVIF Dynamic Learning Program}

In contrast to the tech-for-tech approach, we subscribe to the core-for-tech approach: building on strong fundamentals in scientific principles and the language of mathematics and computer science to facilitate the climb through the educational ladder from elementary school, to junior and senior high school, to college and university, with adaptability for unexpected exit at different steps of the ladder. However, for strong fundamentals to be developed in large student populations, not just the elite (since elitism goes against fair statistical distributions of talent), a solid framework is necessary. We have a design problem that can be stated following the disruptive

\footnotetext{
${ }^{1}$ http://www.china.org.cn/english/2004/Jun/99696.htm (downloaded May 29, 2016), trans. Ni Xiaoqiang: Report on an address of Acad. Wei Yu, Chinese Acad. of Engineering. (See also, for instance, the United States National Science Board report on, "Preparing the Next Generation of STEM Innovators: Identifying and Developing our Nation's Human Capital.”).

${ }^{2}$ https://www.ed.gov/stem.

${ }^{3}$ M. V. Carpio-Bernido, Executive Summary of Invited Plenary Talk, 2016 Annual Scientific Meeting of the National Academy of Science and Technology (Philippines).

${ }^{4}$ http://www.moe.gov.sg/media/parliamentary-replies/2013/10/government-expenditure-on-edu cation.php (downloaded August 5, 2015).

5"State-of-the Nation" reports on 5-14 (2010) and 14-19 (2008) Science and Mathematics Education, Royal Society; https://royalsociety.org/topics-policy/projects/state-of-nation/.
} 
design demand of Henry Ford's Model $\mathrm{T}^{6}$ but modified for educational lingo: "We will design a learning program for the great multitude. It will be large-scale enough for state school systems, but individualized enough for each student in any school, private or state-run, in any part of the country. It will be composed of the best evidence-based features, chosen by the best team to be formed, after the simplest designs that modern pedagogy and learning sciences can devise. But it will be so low in cost that no nation will be unable to effectively implement one." 7

This program, which addresses multifaceted issues, was conceptualized and first implemented in 2002 in a secondary school, the Central Visayan Institute Foundation (CVIF), in Jagna, Bohol, Philippines. The CVIF Dynamic Learning Program $(\mathrm{DLP})^{8}$ works with (i) small input: least cost in human and material resources, in energy — both physical and fuel-and in social cost in terms of learner leisure and family time; and (ii) big output: wide spectrum of learners with high criterion-based performance levels in STEM and other disciplines. The program has built-in mechanisms to mitigate debilitating socioeconomic conditions. Finally, for sustainability the program is systems-based, ${ }^{9}$ with a purposefully designed and controlled coherent learning ecosystem for process-induced learning in contrast to conventional teacherinduced learning. It focuses primarily on developing the learner's biological and intellectual disposition for sustained engagement such that learner performance is much less dependent on teacher and peer personalities, as well as on national and foreign policies.

\footnotetext{
${ }^{6}$ Ford, Henry; Crowther, Samuel (1922), My Life and Work, Garden City, New York, USA: Garden City Publishing Company, Inc. Various republications, including ISBN 9781406500189. Original is public domain in $U S$.

${ }^{7}$ M. V. Carpio-Bernido and C. C. Bernido, Invited talk for the 10th Global Business School Network Annual Conference: Disruptive Education Models from the Developing World, November 2015, Asian Institute of Management, Makati, Philippines; adaptations, with apologies, in italics.

${ }^{8}$ M. V. Carpio-Bernido and C. C. Bernido, "Science Culture and Education for Change, Part I: Innovative Strategies for Secondary Education in the Philippines," Transactions of the National Academy of Science and Technology, vol. 26, No. 2 (2004), pp. 243-267; M. V. Carpio-Bernido and C. C. Bernido, "CVIF Dynamic Learning Program: A Systems Approach to Process-Induced Learning" in epiSTEME 4: International Conference to Review Research on Science, Technology and Mathematics Education, eds. S. Chunawala and M. Kharatmal (Homi Bhabha Centre for Science Education, Mumbai, 2011) pp. 269-273.

${ }^{9}$ L. von Bertalanffy, General System Theory: Foundations, Development, Applications. (New York: George Braziller, 1968).
} 


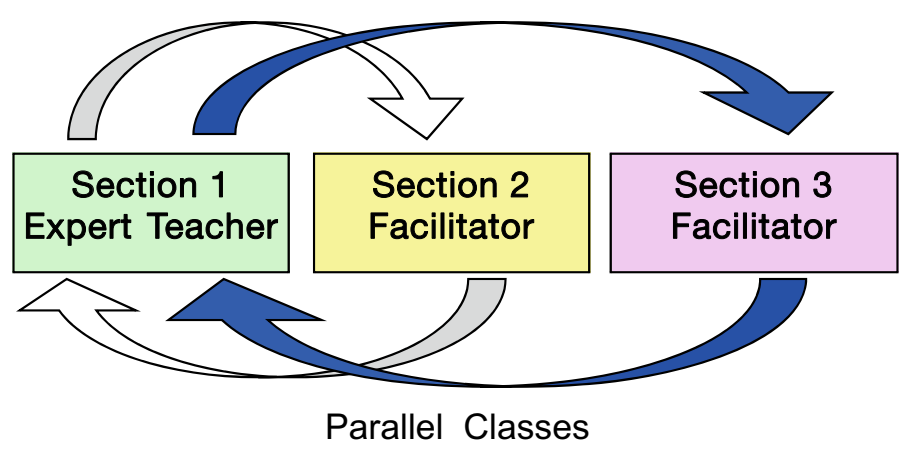

Figure 9.1 Classes for a given subject are held simultaneously for three sections

\section{Essential Program Components}

There are four key pillars in the CVIF-DLP, ${ }^{10}$ which find analogy with efficient practices in other professions and are validated by recent neuroscientific findings. There are other features of the program, but these four components are the most essential and are non-negotiable for faithful implementation, which leads to significantly enhanced outcomes.

\section{Parallel Classes}

A subject or expert teacher handles two or three sections of the same subject simultaneously during one class period (Figure 9.1). This component strategically sets bounds on teacher intervention, because the hallmark of the CVIF-DLP is independent, personally active learning; $80 \%$ of the time the expert teacher is not with the class, which is supervised by a teacher facilitator, who may not be a content expert.

In the context of managerial efficiency, the parallel class approach is able to minimize the number of subject teachers needed, because students are on their own doing learning activities most of the time. The approach, in which there is still structure, is in between the traditional teaching-learning setup and the no-teacher or distance learning setup. It is particularly helpful for alternative learning systems and for learning with online educational resources.

\footnotetext{
${ }^{10}$ M. V. Carpio-Bernido and C. C. Bernido, "Science Culture and Education for Change, Part I: Innovative Strategies for Secondary Education in the Philippines," Transactions of the National Academy of Science and Technology, vol. 26, No. 2 (2004), pp. 243-267; M. V. Carpio-Bernido and C. C. Bernido, "CVIF Dynamic Learning Program: A Systems Approach to Process-Induced Learning" in epiSTEME 4: International Conference to Review Research on Science, Technology and Mathematics Education, eds. S. Chunawala and M. Kharatmal (Homi Bhabha Centre for Science Education, Mumbai, 2011) pp. 269-273.
} 
The parallel classes scheme is an inversion of the Jigsaw Strategy ${ }^{11}$ devised by E. Aronson in 1971 in Austin, Texas, United States, where students are grouped into so-called home groups and expert groups. Each student contributes his or her understanding and explanation of a given concept as students transfer from the expert groups to their home groups. Successful achievement of learning objectives depends on the synergy of contributions. In the CVIF inverted format, the exchange between expert teachers and teacher facilitators enhances the learning process by fostering strategically proportioned independent and collaborative learning with specially designed learning activities.

\section{Activity-Based Learning by Doing}

The emphasis is on strategic thinking, writing, and doing. Students copy by hand and accomplish learning activities without introductory lectures from their subject teacher. Indeed, they do such activities without direct supervision and help from the subject teacher, with the class only managed by a teacher facilitator. This allows students to apply comprehension skills and analytical thinking, while fostering much peer tutoring.

Since 2002, a hallmark of the CVIF-DLP, which has encountered much opposition, is that each new lesson digest to be learned is copied by hand on the Learning Activity Sheet (LAS). For each new topic, all students write the Activity Title, Learning Target, and Concept Digest; draw illustrations; and answer questions (deliberately designed to fit one long-size page, font 14). This seemingly medieval strategy was purposefully chosen to coax learner disposition by such an initially intellectually nonthreatening mechanical action. The daily practice eventually becomes habitforming for most students, and even if initially is resisted, most often there is a turning point at which the students discover whether they like it or not; whether they are aware of it or not; and many eventually find themselves enjoying learning as intellectual stimulation, especially since independent learning gives them more confidence. Thus, such development of biological and intellectual habits bypasses the common problem of motivation, with teachers resorting to song and dance, theater, and fun games, yet observing the rapid decline in motivation when the fun ends. Indeed, intellectual habits are more important when doing advanced activities in physics, chemistry, and calculus, among others. Moreover, copying by hand slows down the learning pace, allowing more time for deeper absorption and understanding of concepts and principles, in contrast to listening to lectures or discussions that often proceed at a rapid pace, especially when teachers are pressured to cover the given scope of competencies. The effect of writing by hand on learning has been analyzed in recent studies. ${ }^{12}$

\footnotetext{
${ }^{11}$ www.jigsaw.org/history.htm.

${ }^{12}$ P. A. Mueller and D. M. Oppenheimer, "The Pen is Mightier than the Keyboard: Advantages of Longhand over Laptop Note Taking," Psychological Science (2014) https://doi.org/10.1177/095 6797614524581; F. Bara and E. Gentaz, "Haptics in Teaching Handwriting: The Role of Perceptual
} 
Finally, since monitoring and evaluation of the progress of learning is extremely important, the accomplished LASs by different classes and grade levels provide an extremely huge source of data for assessment of learning. Prototype LASs have been uploaded for open access from anywhere in the world. For example, a sample LAS in Chemistry may be found at https://eduversum.org/cvif, which is an offshoot of a CVIF collaboration with Science-Corps (see, e.g., https://www.youtube.com/watch? $\mathrm{v}=\mathrm{M} 3 \mathrm{KETUt0O1Q}$ ), a nonprofit organization based in California, United States. With the help of a telecommunication company, Smart Communications, and the PLDTSmart Foundation, a collection of 239 LASs in Physics may also be accessed in the e-learning section of https://dlp.ph, which is an output of the "Learning Physics as One Nation" project of the Fund for Assistance to Private Education (Philippines). ${ }^{13}$

\section{In-School Comprehensive Portfolio}

Portfolios in school have been popular since the last century, but most were for selected school work or mini projects. In the CVIF-DLP, the concept is expanded into a Comprehensive Portfolio for compiling all the daily LASs, small projects, quizzes, and examinations accomplished by the student. A single-subject portfolio could easily be more than 200 written pages when the school year ends, at which time they finally bring this home.

As the compilation of daily LASs and assessments, the portfolio ensures not only that learnings that happen within the day are well documented, but also that the process of systematic organization of data is imbibed - a skill necessary in the world of work.

\section{Strategic Rest}

Since its initial implementation in 2002, the CVIF-DLP has already incorporated (i) a no-homework policy, (ii) a light midweek load (Wednesday for Physical Education, Music, Arts, and Health), and (iii) deterrence against external tutors after school hours. This is because the intensity of learning during school hours necessitates rest and recreation after school, which also makes external tutors unnecessary for enhanced learning. Moreover, parents are advised to make sure their children

and Visuomotor Skills," Human Movement Science (2010), https://doi.org/10.1016/j.humov.2010. 05.015; and K. James and L. Engelhardt, "The Effects of Handwriting Experience on Functional Brain Development in Pre-Literate Children” Trends Neurosci. Educ. 1 (2012) 32-42.

${ }^{13}$ Carpio-Bernido, M. V., Bernido, C. C. and Porio, C. C. (2011) The Learning Physics as One Nation Initiative: Bypassing the National STEM Teacher Shortage. In Proc. of the epiSTEME 4 (Mumbai: HBCSE). 

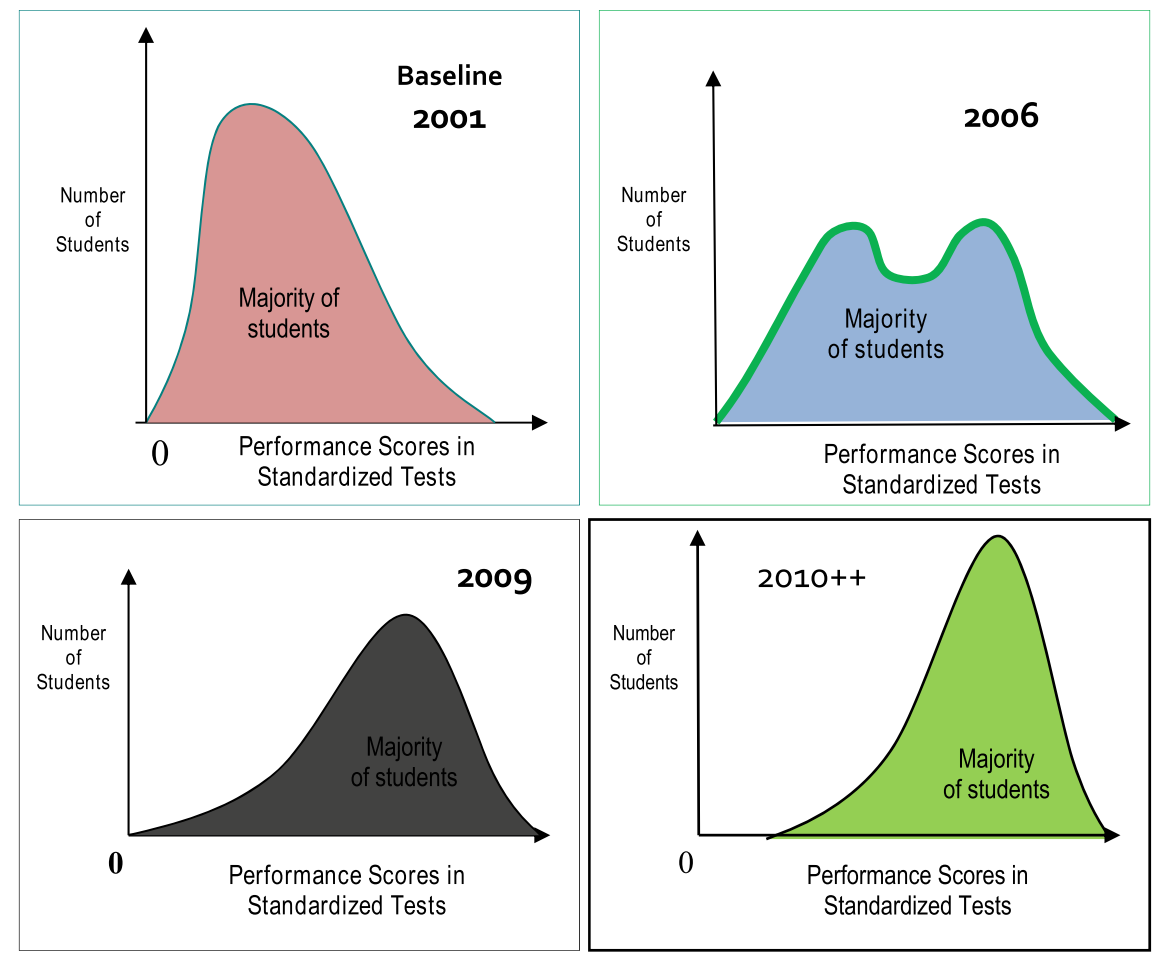

Figure 9.2 Frequency distribution of CVIF students based on percentile rank in national examinations

have enough sleep following the requirements recommended by the National Sleep Foundation. Recent neuroscientific studies also show that sleep is good for learning. ${ }^{14}$

\section{Performance Indicators}

Every year the Philippine Government conducts a national examination, which the CVIF has been monitoring. Figure 9.2 shows the results of the National Scholastic Achievement Test and later the National Career Assessment Exam. Prior to the implementation of the CVIF-DLP in 2002, the majority of the students were clearly underperforming (upper left graph). However, starting in 2010 up to the present

\footnotetext{
${ }^{14} \mathrm{https}$ ://www.sleepfoundation.org/excessive-sleepiness/support/how-much-sleep-do-we-reallyneed (downloaded April 2019); J. M. Saletin, A. N. Goldstein, and M. P. Walker, "The Role of Sleep in Directed Forgetting and Remembering of Human Memories" Cerebral Cortex, 21, (2011) 2534-2541; and J. Tamminen, J. D. Payne, R. Stickgold, E. Wamsley, M. Gaskell, "Sleep Spindle Activity is Associated with the Integration of New Memories and Existing Knowledge," Jour. of Neuroscience, 30 (2010) 14356-60.
} 

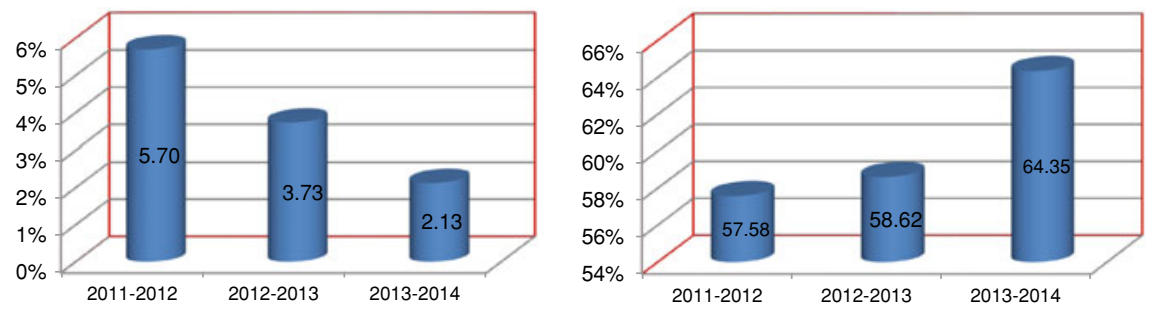

Figure 9.3 Declining failure rate (left) and rising NAT scores (right) in the division of Bohol during the first 3 years of CVIF-DLP implementation

(lower right graph), the truncated tail shows no student having a percentile rank below Below Average, in spite of the fact that the CVIF has a very liberal admission practice, with the majority of incoming Grade 7 students coming from public elementary schools (the CVIF has only a high school department).

In 2011, with the joint efforts of the Department of Education (DepEd) Division of Bohol and the Office of the Governor, more than a hundred public secondary schools in Bohol adopted the CVIF-DLP approach. The results, as reported by a Division of Bohol DepEd official during the annual CVIF-DLP workshops, are improved performance in the National Achievement Test (NAT) and declining failure rate (Figure 9.3), among other behavioral indexes such as the rise in love for learning and the conditions children find at school that keep them in school, hence improving retention. Dropouts and absenteeism have been minimized despite the fact that some children also walk for kilometers to attend school and no additional support is provided to them.

However, after the first 3 years, many administrators tweaked the CVIF-DLP and pursued selective implementation of the program features. A comprehensive assessment of the Bohol implementation is presently being undertaken so as to distill contributing factors to improved learning outcomes.

Many CVIF graduates went on to show exemplary performance in college, and some students were able to get scholarships to prestigious schools abroad. One is pursuing his $\mathrm{PhD}$ in Marine Science at ETH Zurich; another graduated with a BS in Anthropology from the University of California, Berkeley; an alumna is pursuing her PhD in Physics in Germany under the Max Planck Institute-University of Dresden collaboration; and an information and communication technology (ICT) graduate landed a job with Google Philippines within a year of finishing Grade 12.

\section{Conclusion}

Strategizing on and operationalizing the vision of a good school inside the classroom is very important. The CVIF did this by adopting the four key learning pillars encapsulated in the CVIF-DLP (see, e.g., https://www.youtube.com/watch?v=cmYljCepS-8) 
that target the development of learners' disposition and skills development habits helpful for the twenty-first century despite challenges such as the insufficient number of quality teachers, equipment, and textbooks. Through its main features/pillars, the CVIF-DLP fosters the development of the following habits among students: (i) independent learning-because they tackle new lessons without prior lectures, and they are encouraged to comprehend new learning materials and frame answers to questions; this habit-forming feature of the CVIF-DLP will be crucial in the coming decades wherein an individual has to learn several new skills in a lifetime; (ii) organized logical thinking and big picture perspective-developed primarily through the practice of sequential filing of the year-long plan of activities, the daily accomplished activities, examinations, and quizzes into portfolios; and (iii) collaboration and teamwork-enhanced because peer tutoring is pronounced in the CVIF-DLP since subject teachers intervene during only around $30 \%$ of the class period. All these important learning habits can be developed in spite of minimal resources.

Link to the presentation material: https://events.development.asia/materials/201 71212/essentials-over-peripherals-central-visayan-institute-foundation-dynamiclearning.

\section{References}

Bara, F., \& Gentaz, E. (2010). Haptics in teaching handwriting: The role of perceptual and visuomotor skills. Human Movement Science. https://doi.org/10.1016/j.humov.2010.05.015.

Carpio-Bernido, M. V., \& Bernido, C. C. (2004). Science culture and education for change, Part I: Innovative strategies for secondary education in the Philippines. Transactions of the National Academy of Science and Technology, 26(2), 243-267.

Carpio-Bernido, M. V., \& Bernido, C. C. (2011). CVIF dynamic learning program: a systems approach to process-induced learning. In S. Chunawala and M. Kharatmal (Eds.), epiSTEME 4: International Conference to Review Research on Science, Technology and Mathematics Education (pp. 269-273). Mumbai: Homi Bhabha Centre for Science Education.

Carpio-Bernido, M. V., \& Bernido, C. C. (2015). Invited talk for the 10th Global Business School Network Annual Conference: Disruptive Education Models from the Developing World, November 2015. Makati, Philippines: Asian Institute of Management. (adaptations, with apologies, in italics).

Carpio-Bernido, M.V. (2016). Executive summary of invited plenary talk. In 2016 Annual Scientific Meeting of the National Academy of Science and Technology (Philippines).

Carpio-Bernido, M. V., Bernido, C. C., \& Porio, C. C. (2011). The learning physics as one nation initiative: Bypassing the national STEM teacher shortage. In Proceedings of the epiSTEME (vol. 4). Mumbai: HBCSE.

Ford, H., \& Crowther, S. (1922). My Life and Work, Garden City, New York, USA: Garden City Publishing Company, Inc. Various republications, including. ISBN 9781406500189. (Original is public domain in US).

James, K., \& Engelhardt, L. (2012). The effects of handwriting experience on functional brain development in pre-literate children. Trends Neuroscience Education, 1(2012), 32-42.

Mueller, P. A., \& Oppenheimer, D. M. (2014). The pen is mightier than the keyboard: Advantages of longhand over laptop note taking. Psychological Science. https://doi.org/10.1177/095679761 4524581 . 
Royal Society. (2010). State of the Nation reports on 5-14 (2010) and 14-19 (2008) Science and Mathematics Education, Royal Society. https://royalsociety.org/topics-policy/projects/state-ofnation/.

Saletin, J. M., Goldstein, A. N., \& Walker, M. P. (2011). The role of sleep in directed forgetting and remembering of human memories. Cerebral Cortex, 21, 2534-2541. https://www.sleepfoun dation.org/excessive-sleepiness/support/how-much-sleep-do-we-really-need (downloaded April 2019).

Tamminen, J., Payne, J. D., Stickgold, R., Wamsley, E., \& Gaskell, M. (2010). Sleep spindle activity is associated with the integration of new memories and existing knowledge. Journal of Neuroscience, 30(2010), 14356-14360.

von Bertalanffy, L. (1968). General system theory: foundations, development, applications. New York: George Braziller.

Xiaoqiang, N. (2004) Report on an address of Acad. Wei Yu, Chinese Acad. of Engineering. (See also, for instance, the United States National Science Board report on, "Preparing the Next Generation of STEM Innovators: Identifying and Developing our Nation's Human Capital.”). http:// www.china.org.cn/english/2004/Jun/99696.htm (downloaded 29 May 2016), trans. https://www. ed.gov/stem. http://www.moe.gov.sg/media/parliamentary-replies/2013/10/government-expend iture-on-education.php (downloaded 5 August 2015). www.jigsaw.org/history.htm.

The views expressed in this Chapter are those of the authors and do not necessarily reflect the views and policies of the Asian Development Bank (ADB) or its Board of Governors or the governments they represent.

ADB does not guarantee the accuracy of the data included in this Chapter and accepts no responsibility for any consequence of their use. The mention of specific companies or products of manufacturers does not imply that they are endorsed or recommended by ADB in preference to others of a similar nature that are not mentioned.

By making any designation of or reference to a particular territory or geographic area, or by using the term "country" in this Chapter, ADB does not intend to make any judgments as to the legal or other status of any territory or area.

This work is available under the Creative Commons Attribution 3.0 IGO license (CC BY 3.0 IGO) https://creativecommons.org/licenses/by/3.0/igo/. By using the content of this Chapter, you agree to be bound by the terms of this license. For attribution, translations, adaptations, and permissions, please read the provisions and terms of use at https://www.adb.org/terms-use\#openac cess.

This CC license does not apply to non-ADB copyright materials in this Chapter. If the material is attributed to another source, please contact the copyright owner or publisher of that source for permission to reproduce it. ADB cannot be held liable for any claims that arise as a result of your use of the material.

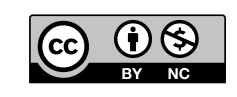

